\title{
O ludicamente sério e o seriamente lúdico de Georges Perece
}

Jacques Fux $\%$ Doutor em Literatura Comparadå pela UFMG e Docteur em Langue,

Resumo: Este artigo tem como objetivo apresentar algumas das contraintes utilizadas na obra de Georges Perec. Inicialmente es: sas restrições parecem apenas ingênuas e lúdicas. Porém, ana:lisando detalhadamente seu contexto e sua estrutura, encontra:mos diversas e potenciais interpretações.

Palavras-chave: OULIPO, Georges Perec, jogos literário.

Abstract: This article aims to present some of the contraintes used in the work of Georges Perec. Initially, these constraints only seem

Jittérature et civilisation frannçaises pela Univèrsité Charles-de-Gaulle. Professor da PUC-MiG.

e-mail: jacfux@gmail.com naive and playful. However, after a deeper analysis of its context and structure, we found several potential interpretations.

Keywords: OULIPO, Georges Perec, literary games.

\section{As sciences dhres a as sciences molles}

Escrever um pequeno texto excluindo uma determinada letra, homenagear alguém utilizando seu nome para iniciar cada um dos parágrafos de um documento qualquer, descobrir palavras e frases que podem ser lidas da direita para esquerda e da esquerda para direita, encontrar relações interessantes entre os números primos, pares, ímpares são brincadeiras comuns e que muitos já fizeram. O problema central dessas brincadeiras consiste no fato da extrapolação do limite do lúdico, ou seja, levar a brincadeira ao extremo da dificuldade implica tornar o jogo sério e bem estruturado.

Em francês, a matemática é considerada como uma ciência dura, uma ciência difícil de trabalhar, de entender e de recepcionar (muitas vezes). Perec e o OULIPO propõem, através das ciências moles, trabalhar e recepcionar obras construídas e elaboradas por meio de contraintes, muitas delas originadas das ciências duras. A questão da recepção e da potencialidade se torna de suma importância: um leitor que não é versado na matemática será capaz de compreender e assimilar o jogo que o texto propõe? A recepção de um texto qualquer e de um texto com enigmas, jogos e contraintes é diferente? A brincadeira só se torna séria diante da percepção do leitor? A partir da descrição das contraintes de 
Perec e de suas relações com a matemática, tentaremos discutir essas perguntas.

\section{Descrição das comtruintes nas obras de Georges Perec}

Podemos conjecturar que Georges Perec conhecia bem todos os acordos do OULIPO. Mesmo antes de sua entrada no grupo, já manipulava certas restrições em seus trabalhos e já conhecia a arte combinatória utilizada por Raymond Queneau. Sua obra, a partir do momento de sua união ao grupo, representa conscientemente suas diretrizes. Assim, ao se tornar membro do OULIPO, Perec começa a trabalhar com palíndromos 1 ; lipogramas ${ }^{2}$, xadrez, go ${ }^{3}$, lógica, anagramas ${ }^{1}$. 'Escreve um livro inteiro sem o uso da letra e: La disparition. Cria posssivelmente o maior palíndromo conhecido na época, composto por cinco mil palavras, "Palindrome" (PEREC, 1973b, p.97-102). Escreve um conto chamado "What a Man!" (PEREC, 1996), nio qual disçute a história de dois personagens, Andras MacAdam e Armanid d'Artagnan, utilizando apenas å vogal $a$.

Em muitos momentos, Pérécescreve que à literatúra (assim cómo a arte do puzzle) é um jogo que se joga a dois ${ }_{i}$ na qual cảda forma de leitura foi pensada anteriormente pelo autor, controlando assim todas as suas possibilidades. Porém, ele próprio discorda e refuta, o tempo todo, esse jogo entre autor e leitor. Por mais matemático e estruturado que o projețo literário seja; quando a obra alcança o público, leitura e recepção não estão mais nas mãos do construtor de puzzles.

De forma lúdica, Perec trabalha problemas importantes dentro da literatura como o projeto de totalidade e de esgotamento. Tentando descrever tudo o que se passa em uma praça em Paris, compõe o livro Tentative d'épuisement d'un lieu parisien (PEREC, 2003a); e, com o intuito de pensar em todas as possibilidades de se pedir um aumento ao chefe, escreve $A$ arte e a maneira de abordar seu chefe para pedir um aumento (PEREC, 2010). Entretanto, Perec está ciente da limitação, e através dessa tentativa absurda da totalidade e do esgotamento, critica qualquer projeto que tente abarcar o todo.

Essa crítica pode ser estendida ao conceito de leitor ideal: por mais versado e idealizado que o leitor perecquiano ou oulipiano seja, a totalidade e o esgotamento são inatingíveis. A própria contrainte se encarrega dessa impossibilidade, já que, por vezes, a combinatória é utilizada (como no caso do Cent mille milliards de poèmes, de Raymond Queneau) ou o erro é inserido no sistema, como veremos adiante.

I Um texto de tamanho indeterminado, cujas letras pôdem ser lidas da direita para esquerda ou ao contrário, como se vê em "AMOR - ROMA".

2 Um texto que exclui uma ou mais letras do alfabeto.

Jogo chinês conhecido por sua complexidade e pelo grande número de combinações possíveis.

4 Transposição de letras de palavras ou de frases, a partir da qual uma nova palavra ou frase é formada. 


\subsection{A vida modo de usar}

No dia 26 de outubro de 1976 morre Raymond Queneau. Nesse mesmo dia, Georges Perec começa a escrever $A$ vida modo de usar, dedicado a seu grande amigo então falecido. De grande complexidade e construído sob contraintes, o livro trata de histórias inter-relacionadas de habitantes de um mesmo prédio situado à 11 Rue Simon-Crubellier. Assim escreve Perec em Espèces d'espaces sobre seu futuro livro:

Eu imagino um prédio parisiense com a fachada removida [...] de tal maneira que da entrada até os quartos de empregada, todos os apartamentos possam ser vistos instantaneamente e simultaneamente. O romance, de título $A$ vida modo de usar, se limita (se eu ouso utilizar esse verbo para um projeto que em seu desenvolvimento final terá algo em torno de 400 páginas) em descrever os apartamentos que aparecem e as atividades que se desenvolvem (PEREC, 2000, p. 53).

Assim Claude Burgelin descreve A vida modo de usar:

Construir a torre de Babel, escrever um romance que contenha todos os tipos de romances; coloçar em cena dezenas de vidas simultaneamente; evocar modos de usar da existência tão diversa quanto póssível; deixar seguir múltiplos tempos a partir desse éspaço fechado; obrigar a evocação de milhares de o̊bjętos, emblemas, imagens e dar vida a esse propósito; juntar o prazer da infância (jogos, encaixes, listas, quebra-cabeças, livros de aventuras, trocadilhos, adivinhas, cadeias ao infinito) e combinatórias mais sofisticadas; abolir, subverter, ultrapassar fronteiras entre texto e imagem, narrativa e ícones, transformar a literatura em uma cópia miniaturizada do mundó e da literatura; aprender a olhar e ler errando sem parar; metamorfosear o enciclopedismo em material romanesco; estruturar claramente um romance labiríntico, tornar móvel um romance-imóvel, dirigir um romance-jogo de xadrez (em todos os sentidos da palavra). Estas são algumas das proezás do acrobata Perec. (BURGELIN, 1988, p. 177). $\because$

O projeto de $A$ vida modo de usar é rigoroso $0^{\circ}$ bem estrúturado, assim como um jogo. A composição do liviro explora trếs principais estruturas: Bicarré latin orthogonalơ d'ordre 10, la polygra-

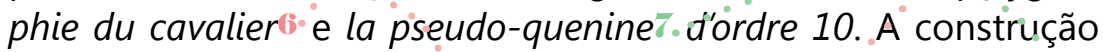
lógica e definida sob regras nos remete ao teor axiomático da

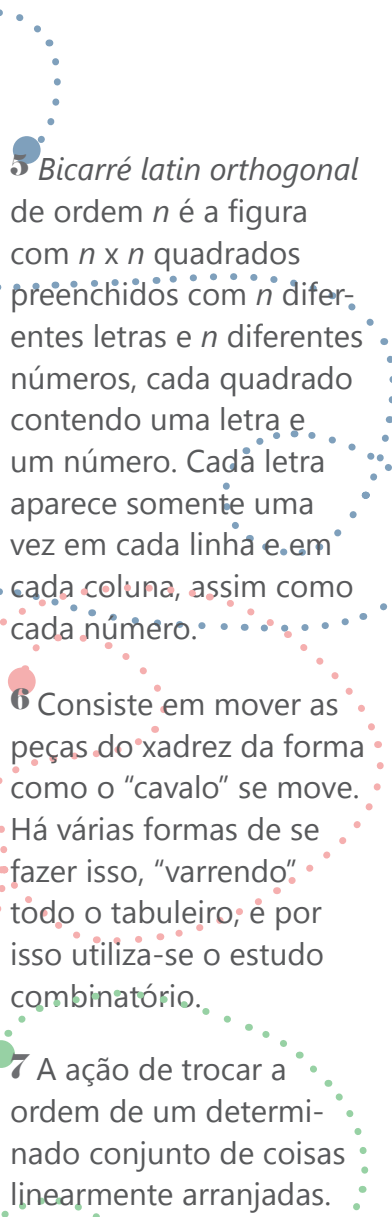


matemática. Entretanto, o objetivo proposto não é concretizado, como descrito a seguir:

É o dia 23 de junho de 1975, e vão dar oito horas da noite. Sentado diante do puzzle, Bartlebooth acaba de morrer. Sobre a toalha da mesa, nalgum lugar do céu crepuscular do quadringentésimo trigésimo nono puzzle, o vazio negro da única peça ainda não encaixada desenha a silhueta quase perfeita de um $X$. Mas a peça que o morto segura entre os dedos, já de há muito prevista em sua própria ironia, tem a forma de um W. (PEREC, 1991, p. 578).

Essa não concretização do projeto pode ser encarada também como uma das contraintes que Perec utiliza para a confecção de sua máquina de contar histórias, a chamada manque (falta). Há também uma relação deste projeto não acabado com sua obra, sua incompletude em relação à tentativa de controlar todas as possibilidades e combinações de leitura e escrita.

\subsection{Outras brincadeiras sérias}

Outro aspecto lúdico na obra de Perec é a utilização de recursos formais. Inicialmente visto como um jogo, também tem como objetivo discutir e problematizar diferentes aspectos da literatura. A utilização dos recursos formais na obra de Perec é sua tentativa de fugir do acaso, de controlar aquilo que não é controlável, de mudar e dominar o destino de todas as coisas, o que reflete muito sua história pessoal. Já a utilização da simetria bilateral pode ser encontrada em vários de seus textos e livros, como em Espèces d'espaces: "Eu escrevo: eu traço palavras numa página. [...] Antes não havia nada, ou quase nada: após, não há grande coisa, alguns sinais, mas que são suficientes para que haja um alto e um baixo, um começo e um fim, uma esquerda e uma direita, um reto e um verso." (PEREC, 2000, p. 18).

Inicialmente de simples entendimento e concepção, o palíndromo é muito presente em Perec e reflete o jogo entre o lúdico e o sério. Podemos começar a entender o palíndromo, sua tentativa de escapar do acaso, do incontrolável e, por isso, sua utilização simétrica. Uma explicação mais profunda em relação aos conflitos internos e à história pessoal do autor pode ser encontrada nos estudos de Bernard Magné:

Mas, se tratando de Perec, o palíndromo permite uma leitura de duplo sentido, exibe uma dupla escritura, conflitante, onde a orientação direita esquerda se encontra recoberta, mascarada, dominada pela existência do texto padrão, como na escritura judaica em Perec, rebaixada ao nível de escritura jamais 
esquecida, mas, pior ainda, jamais sabida: "Eu não falo a língua que meus pais falavam". Desta língua ausente, o palíndromo é o traço e a memória. Não surpreende a sua onipresença na obra perecquiana. (MAGNÉ, 1999, p.84).

Aos dois palíndromos publicados por Perec - À Pierre Getzler (PEREC, 1970), constituído por 589 letras, e 9691 EDNA D'NILU O, UM, ACÉRÉ, PSEG ROEG (PEREC, 1973b), formado por mais de 5000 letras e que figura no livro Guiness de Records - podemos ainda juntar outros micropalíndromos presentes em sua obra. Em La disparition (1969a), temos alguns, como Noyon, S.O.S, nommons, mon nom, Radar, lit-il. Em $W$ ou a memória da infância (1995a), temos Otto, bob, selles. Em A vida modo de usar (1991) temos um palíndromo com o "Tlön Uqbar Orbis Tertius", de Jorge Luis Borges: "Boris Baruq Nolt". Na obra de Perec, podemos observar que a utilização dos palíndromos (bem como a utilização de todos as contraintes) está relacionada com a simetria e com a tentativa do escritor de controlar o acaso.

Outro recurso de simetria bem trabalhado por Perec é a chiasme, que consiste em um cruzamento de elementos de uma frase ou de um conjunto de frases que tem por objetivo dar ritmo ou estabelecer paralelos entre elas. Pode também estabelecer a ligação entre dois elementos ou reforçar sua antítese. Alguns exemplos de chiasmes podem ser encontrados em Quel petit vélo à guidon chromé au fond de la cour (PEREC, 2002b) e em La disparition.

Destacam-se ainda nesse campo o lipograma e o clinamen. $O$ lipograma, texto em que o autor se impõe a restrição de não empregar uma ou várias letras, constituiu uma manifestação formal da contrainte falta (manque), trabalhada em $A$ vida modo de usar. Seu texto mais conhecido no qual esse recurso é aplicado é $L a$ disparition, escrito sem utilizar a letra $E$.

A letra $E$ aparece quatro vezes em Georges Perec, duas em seu nome e duas em seu sobrenome. Perec perdeu seus pais na $2^{a}$ Guerra Mundial e, segundo muitos estudos, a privação da letra E seria a privação da letra mais importante do alfabeto, representando a falta das pessoas mais importantes de sua vida, conforme afirma o próprio Perec em $W$ ou a memória da infância e em La disparition:

Eu escrevo [...] porque eu fui um entre outros. Eu escrevo sem $E$, eu escrevo sem eles, $E$ e eles estão inseparavelmente ligados, ausentes/presentes, eles presentes no livro como na letra tabu sempre aqui em filigrana, jamais escrito e sempre convocado pela perífrase, metáfora, comparação ou metonímia. Breve, o lipograma, ou como dizer (como se calar?) o indizível. (MAGNÉ, 1999, p. 41). 
Outras variações lipogramáticas podem ser encontradas em seus trabalhos. A contrainte do prisioneiro deseja que um prisioneiro em sua cela, que dispõe de muito pouco papel, escreva a maior carta possível. Neste caso, as letras que ultrapassam as linhas são proibidas (é o caso, por exemplo, do $p$, que ultrapassa a linha para baixo, e do $b$, que ultrapassa a linha para cima). Perec ainda se proíbe utilizar letras como o $i$ e o e acentuados. Menos conhecido, ele usa também o palíndromo vertical, no qual só são admitidas letras que, após uma rotação de $180^{\circ}$, continuem idênticas (caso das letras $0, s, x, z, i)$ e letras que se transformam em caracteres diferentes após a sua rotação de $180^{\circ}$, tais como: (a ${ }^{(R)}$ $\left.\mathrm{e}, \mathrm{b}^{(\mathrm{R})} \mathrm{q}, \mathrm{d}^{(\mathrm{R})} \mathrm{p}, \mathrm{n}{ }^{(\mathrm{R})} \cdot \mathrm{u}\right)^{\circ}$ ássim como a frase: andin basnoda a une epouse qui pue. ${ }^{2}$ Assim, nas palavras de Bernard Magné:

Considerar o lipograma como uma das figuras canônicas na engrenagem da fálta, permite, mie parece, compreender as razões profundas de tál atração por essa contrainte. Se Perec é um "lipogramamaníaco", não é por qualquer gosto perverso, por uma extravagância que a história literária respeitável foi engendrada a denunciar. Dando novamente à palavra todos os seus sentidos, ele faz do lipograma o fundamento de um trabalho que visa, pacientemente, meticulosamente, obstinadamente, texto após texto, a elaborar uma autêntica escritura de falta (MAGNÉ, 1999, p. 42).

Já o clinamen, aplicado à literatura pelo pataphysique Alfred Jarry, faz referência à filosofia de Epicuro - le monde fonctionne parce que, au départ, il y a un déséquilibre - e também ao pintor alemão Paul Klee - le génie, c'est l'erreur dans le système (PEREC, 2003b, p. 201). Sua utilização pelo OULIPO e por Georges Perec está relacionada a um desvio de contrainte, a uma falta em relação à regra ou a uma variação dela. Em relação a Perec, este clinamen aparece em Les revenentes, em que a regra não está presente ou aparece burlada em alguns momentos (Perec por vezes escreve algumas palavras erradas para poder utilizar somente a vogal E). Porém, o exemplo mais importante que podemos encontrar está em $A$ vida modo de usar. o clinamen em relação ao número de capítulos. Como Perec construiu um tabuleiro de $10 \times 10$, espera-se 100 capítulos; porém, há somente 99. O clinamen está na ausência de um capítulo. Entretanto, em relação ao sistema de contraintes, aparecerão sempre 42 elementos em cada capítulo, dentre os quais há a contrainte falta (manque), uma recursividade ou uma crítica à classificação. De acordo com Perec:

Isso me deu a ideia de suprimir um capítulo, de modo que não se possa reconstituir o sistema que só existe para mim e que eu gostaria um pouco "tour

Sem considerar o "pingo".

9 Andin Basnoda tem

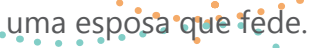

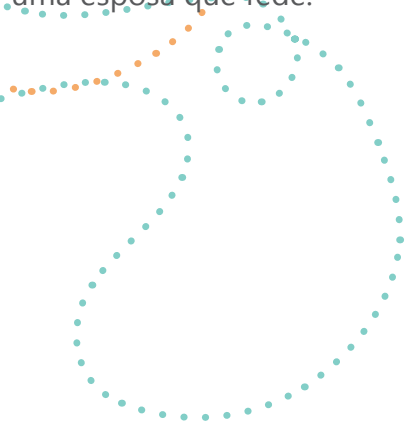


de piser", tornar um pouco manco em alguma parte: era necessário que houvesse um erro, mas esse erro não podia ser deixado ao acaso completo por várias razões. Quer dizer, um quadrado de dez por dez parece bastante um biscoito amanteigado, onde começamos sempre a comer um canto. Ou, há a pequena menina que aparece no fim do capitulo 65 : ela morde um biscoito amanteigado e cai o capítulo seguinte tão bem que toda a numeração seguinte é falsa (PEREC, 2003b, p. 166).

Para Perec, é necessário destruir a simetria a fim de introduzir um erro no sistema, o que será, portanto, uma anti-contrainte. Não se pode ser rígido, é importante que continue a existir o jogo, e por isso o clinamen.

\subsection{O Lipograma e seus (novos).jogos interessantes}

Para Perec, o Lipograma pode ser considerado como o grau zero da contrainte - já que seu entendimento é bem simples e direto (ainda que sua aplicação, algumas vezes, seja bastante difícil) -, a partir do qual toda literatura em contrainte se torna possível:

Neste sentido, a eliminação de uma letra, de um sinal tipográfico, do suporte elementar, é uma operação mais neutra, mais limpa, mais decisiva, qualquer coisa como o grau zero da contrainte a partir do qual tudo se torna possível. (PEREC, 1973a, p. 85).

Em "Histoire du Lipogramme" (1973a), Perec justifica a importância e a utilização de contraintes, por ele e pelo OULIPO. Seu objetivo é traçar um paralelo entre a Cabala, este conhecimento sagrado e soberano e a aplicação, por vezes natural e espontânea ao longo da história, de textos lipogramáticos.

Construindo seu argumento inicial, Perec critica aqueles que ignoram a escritura como prática, como trabalho e como jogo (que é exatamente o que ele faz em toda sua obra). Ele deseja que esta dimensão seja respeitada, que a utilização de regras seja considerada, já que a própria linguagem é uma contrainte:

Essa ignorância lexicográfica acompanha um desconhecimento crítico também tenaz e negligenciado. Unicamente preocupado com suas grandes maiúsculas (a Obra, o Estilo, a Inspiração, a Visão do Mundo, as Opções fundamentais, a Genialidade, a Criação, etc.). [...] As contraintes são tratadas como aberrações, monstruosidades patológicas da linguagem e da escritura; as obras que suscitam não têm o direito do status de obra: doentes, de uma 
vez por todas, em sua proeza e sua habilidade, tornam-se monstros paraliterários justificados somente por uma semiologia onde a enumeração e a fadiga ordena um dicionário da loucura literária. [...] Não pretendemos que os artifícios sistemáticos se confundam com a escritura, mas somente que eles se constituam como uma dimensão não negligenciável. (PEREC, 1973a, p. 75).

Em La disparition, um romance de cerca de 320 páginas, com 78.000 palavras e 297.000 sinais, Perec utiliza a terceira tradição, eliminando a letra mais frequente do francês, em uma contrainte da mais alta dificuldade: "a terceira tradição do lipograma é a tradição vocálica, aquela que bane as vogais. Ela não é necessariamente a mais difícil, escrever sem a letra $a$ em francês é banal, mas difícil em espanhol; o inverso é para o e" (PEREC, 1973a, p. 83). A eliminação da letra $e$ impede a utilização de três quartos das palavras em francês, além de impedir o uso de termos indispensáveis no idioma, como le, de, que, ne, en, o que faz com que o ambiente feminino se torne difícil e que o adjetivo seja sempre masculino.

Entre os anos de 1981 e 1982, Perec e Jacques Bens escreveram para as revistas Ça m'intéresse, Jeune Afrique e Jeune Afrique Économie uma série de jogos "que podem ser classificados em oito categorias: palavras cruzadas, provérbios escondidos, enigmas, mensagens codificadas, lógica clássica ou cálculo, testes, acrósticos, anagramas ou jogos de letras" (PEREC, 1997, p. 6). Esses jogos já tinham sido utilizados, algumas vezes escondidos, em vários livros de Perec; porém, para essas revistas, ele propõe os jogos apenas explicitamente. Para ele, escrever e brincar são quase a mesma coisa: "a escritura é um jogo que se joga a dois" (PEREC, 1997, p. 6). Essa ideia de escritura como jogo também é trabalhada na introdução de $A$ vida modo de usar, quando o autor comenta que, apesar das aparências, o puzzle não é um jogo solitário, já que cada jogada, cada intuição, cada esperança, cada cálculo do leitor/jogador foi pensado anteriormente pelo autor. Por isso, para Perec, o romance policial funciona, com suas trapaças e mistérios, como um romance eficaz, como uma atividade lúdica superior.

Em toda sua obra, Perec discute com seu leitor, com todos os leitores, com o leitor oulipiano, com o leitor ideal. E, assim como o leitor, o escritor deve ter pensado, ou tentado pensar, embora inutilmente, em todas as possibilidades de leitura, como num jogo de go ou de xadrez, numa discussão infinita entre a mensagem que foi pensada e a que foi recebida: "A vista segue os caminhos que Ihe foram preparados na obra." (KLEE apud PEREC, 1991, p. 13). 
Nos itens anteriores foram apresentadas algumas contraintes que encontramos na obra de Georges Perec. Outras tantas não foram trabalhadas nem muito menos descobertas ainda. Entretanto, já possuímos as ferramentas mais utilizadas por Perec para discutirmos o lado sério dessas brincadeiras que propomos neste artigo. São elas: a Matemática e a questão da recepção que sustentará a relação entre o lúdico, a contrainte, a literatura e a matemática.

\section{I. A Matemática}

Bernard Magné, no artigo "Georges Perec et les mathématiques" (1999), apresenta Perec como um jovem que não gostava muito de matemática, mas que era bastante interessado e intrigado pelos grandes e também simples problemas da matemática. Perec utilizou, sobretudo, três regras matemáticas e - como em quase todos os aspectos de sua obra - tentou esgotar suas possibilidades. Perec constrói uma aritmética original, com seus próprios valores e seus próprios símbolos, sem referência à numerologia clássica e, assim como a gematria está presente na Cabala, desenvolveu uma geometria fantasmatique que repousa sobre algumas figuras, pouco numerosas, mas muitas vezes recorrentes, que determinam as estruturas formais de seu texto (MAGNÉ, 1999, p. 75). Essas estruturas recorrentes são, essencialmente, o carré e as "simetrias bilaterais". O carré pode ser visto como um tabuleiro clássico de xadrez $(8 \times 8)$, um outro tabuleiro presente em $A$ vida modo de usar (de tamanho $10 \times 10$ ), ou ainda um de $9 \times 9$ presente no Deux cent quarente-trois cartes postales (PEREC, 1999a). Já a simetria bilateral pode ser vista por meio do jogo de palíndromos, da utilização das letras $W$ e $X$ e de suas devidas representações geométricas e da combinatória, presentes, por exemplo, em Alphabets (PEREC, 2001c).

A aproximação entre a matemática de Perec e a verdadeira matemática é claramente simplista, já que Perec era um amador na área. Sua utilização por Perec se deve ao amor que ele nutria por jogos e contraintes e, logicamente, por sua vinculação ao grupo OULIPO. A estrutura bicarré latino utilizada em $A$ vida modo de usar, por exemplo, foi dada a Perec por Claude Berge, matemático membro do OULIPO: "Em 1967, durante uma sessão do OULIPO, tive a oportunidade de conversar com Georges Perec sobre o projeto que realizou com o título de Carrés Latinos, um primeiro rascunho do que se tornaria $A$ vida modo de usar (BERGE apud MAGNÉ, 2002, p. 643).

Em $A$ vida modo de usar encontramos alguns personagens que trabalham com a matemática - Mortimer Smautf, Carel Van Loorens, Abel Speiss - são, como quase todos os personagens do 
livro, obsessivos. Smautf passa sua vida calculando exaustivamente fatoriais em busca do infinito; Loorens exerce várias atividades, de cirurgião à geômetra, ensinando também matemática em Halle e astronomia em Barcelona; Speiss preenche seus dias resolvendo problemas diversos da lógica e da matemática com grande facilidade (PEREC, 1991). Perec, ele mesmo, tinha a obsessão declarada "de preencher um corredor da biblioteca nacional, de utilizar todas as palavras da língua francesa, de escrever tudo que é possível a um homem de hoje escrever." (MAGNÉ, 2002, p. 12).

Em matemática, o conceito de indução matemática visa demonstrar que uma propriedade é válida para todos os números naturais. Para essa demonstração são necessários dois passos:

a) que a propriedade satisfaça, para o termo 0 ou para o primeiro termo de uma série ou progressão;

b) se essa propriedade é válida para um número inteiro $n$, então ela deve ser satisfeita para o seu sucessor, ou seja, $\mathrm{n}+1$.

Uma vez satisfeitos os passos $a$ e $b$, podemos concluir que a propriedade é válida para todos os elementos do conjunto em questão.

O aspecto enciclopédico na obra de Perec pode ser comparado ao aspecto indutivo e esgotante da matemática. Perec queria utilizar todas as palavras e possibilidades da língua francesa, além da potencialidade e do processo de criação formalista da matemática. Os formalistas, na área da matemática, são aqueles que acreditam que a matemática não existe anteriormente ( $a$ priori), que podemos criar regras lógicas e, em seguida, utilizá-las 10 . Essa lógica está para a matemática assim como as palavras estão para Perec. O processo de indução matemática visa demonstrar a validade de uma propriedade para todos os números naturais, assim como a obra de Perec visa esgotar todas as possibilidades da literatura.

Perec tinha também uma obsessão pelos números, sendo considerado, além de um manipulador de palavras e letras, um manipulador também de números e cifras (PEREC, 2002a). Em Je me souviens, escreve: "Eu me recordo da teoria matemática da transitividade. Eu me recordo que todos os números cuja soma de seus elementos dão um total de nove são divisíveis por nove (às vezes, eu passava as tardes a verificar)." (PEREC, 1978b, p. 285). E também em suas palavras, em 53 jours: "As nove maneiras onde o número 53 faz parte de uma sequência de Fibonacci. Os Holandeses dizem que todo número pode ser a soma de seus $\mathrm{K}$ primos (Conjectura de Goldbach)." (PEREC apud MAGNÉ, 1999, p. 65).

Em Matemática há um campo de estudos chamado Teoria dos Números, que trabalha com as propriedades dos números inteiros e no qual há muitos problemas em aberto. Denominamos

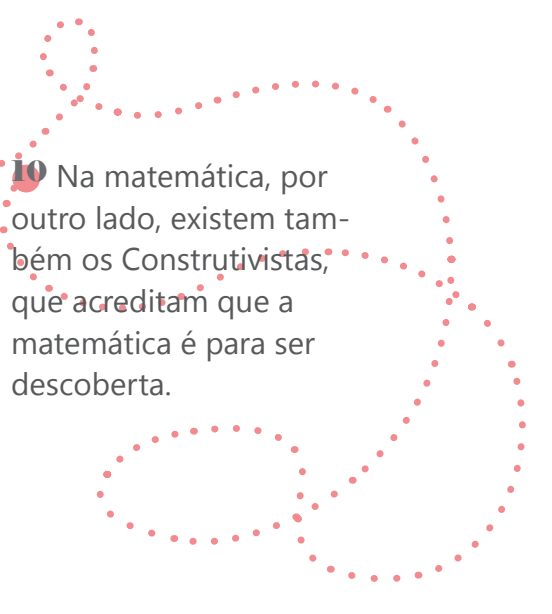


número primo, por exemplo, aquele que tem apenas 2 divisores; o 1 e ele mesmo. Já um número composto é um número formado pela multiplicação de outros números não nulos. O número 12 é um número composto, já que é formado pela multiplicação de 12 $=2 \times 6$ (o 12 pode ser dividido: $1,2,3,4,6,12$, o que não o deixa na categoria de primo). Já o 11 é um número primo, pois seus únicos divisores são o 1 e o 11 . Os primeiros números primos inferiores a 100 são: $2,3,5,7,11,13,17,19,23,29,31,37,41,43$, 47, 53, 59, 61, 67, 71, 73, 79, 83, 89 e 97.

Em Perec, lipogramas, palíndromos e as contraintes do jogo de xadrez podem ser representados como de natureza matemática. Segundo Christelle Reggiani, "estamos então face a uma concepção instrumental da relação entre matemática e invenção literária: a matemática será retida pela atitude oulipiana em razão do seu caráter formal, evidentemente interessante para uma literatura que se escreve essencialmente em torno de estruturas." (REGGIANI, 1997, p. 58). Em seguida, ela traça um paralelo entre a literatura dos componentes do OULIPO e o Bourbaki: "[...] o trabalho oulipiano se coloca, dizendo de outra forma, como uma refundação axiomática da literatura, de acordo com o modelo operado pelos matemáticos do Bourbaki" (REGGIANI, 1997, p. 57).

Assim, Perec brinca seriamente com a matemática, com suas regras, com seus conceitos e com suas estruturas. Partindo da mãe das ciências e dos conhecimentos de outros membros do OULIPO, constrói a sua obra peculiar. Essa literatura-matemática estende-se também por entre os conceitos comparatistas, possibilitando que analisemos as semelhanças e diferenças de utilização entre uma e outra. O situar-se entre permite que a leitura dessas obras não se ressinta de um conhecimento matemático mais profundo, o que lhe garante níveis de leitura diversos. Caso nos detivéssemos apenas ao discurso da matemática, o não conhecimento de suas regras, axiomas, teoremas e da dedução lógica seria impeditivo. Mas o fato de propormos uma leitura que se institui entre duas linguagens, entre a literatura e a matemática, permite que por essas obras transitemos valendo-nos dos recursos dos dois discursos. Desta forma, é possível adentrar as obras de Perec como leitores com ou sem conhecimento matemático, que conhecem ou não a solução dos enigmas, a dificuldade dos paradoxos e a enorme variedade combinatória que as estrutura.

\subsection{A recepção}

De acordo com Jacques Derrida, "um texto só é um texto se ele oculta ao primeiro olhar, ao primeiro encontro, a lei de sua composição e a regra de seu jogo. Um texto permanece, aliás, sempre imperceptível. A lei e a regra não se abrigam no inacessível de um segredo, simplesmente elas nunca se entregam, no presente, 
a nada que se possa nomear rigorosamente na percepção." (DERRIDA, 1991, p. 7). Dessa forma os textos construídos pelas contraintes não se entregam ao primeiro olhar, suas regras e sua composição escondem e ludibriam o leitor.

Em W ou a memória da infância, Perec escreve: "Uma vez mais, as armadilhas da escrita se instalaram. Uma vez mais, fui como uma criança que brinca de esconde-esconde e não sabe o que mais teme ou deseja: permanecer escondida, ser descoberta." (PEREC, 1995a, p. 14). É apenas após a publicação póstuma de seu Cahier de charges (1993) e de diversas entrevistas, que suas invenções, suas contraintes, sua matemática e sua literatura começam a ser reveladas. Sua obra, constituída através de contraintes, pode ser considerada uma forma contemporânea de enigma, diante da qual a posição do leitor se torna ainda mais repleta de potencialidade. A leitura, assim, é participação na criação, é um diálogo com o texto e o autor, concepção na qual se inserem tanto os leitores oulipianos quanto os perecquianos. E como esse leitor se situa em relação à utilização das brincadeiras e das contraintes de Perec? Ao analisar o processo de leitura, Iser escreve, "é um potencial que se atualiza no processo da leitura" (ISER, 199, p. 15), não sendo atribuída sua primordialidade nem ao autor, nem ao leitor. As contraintes, então, em Perec, serviriam para aumentar o efeito potencial do processo de leitura: partindo do emprego de estruturas e conceitos matemáticos e do conhecimento do leitor acerca desses procedimentos, argumentamos que, quanto maior o conhecimento do leitor, maior a potencialidade de sua leitura.

Entretanto, ao estudarmos o OULIPO e analisarmos a estrutura da obra de Queneau, Cent mille milliard de poèmes, observamos uma volta ao leitor "fora de jogo" (COMPAGNON, 2006). Estamos diante de uma inovação, de uma obra em que é necessária a intervenção concreta do leitor na realização das combinações matemáticas propostas. Ao mesmo tempo, sabemos que esse leitor necessário e ativo não irá alcançar, de fato, toda a potencialidade da obra, devido ao grande número de combinações que possibilita.

Esse problema, o do esgotamento das possibilidades de leitura, é levantado pelo próprio Perec na introdução de $A$ vida modo de usar, no qual ele afirma haver pensado em todas essas possibilidades e, ao final da obra, como indicamos anteriormente, demonstra o fracasso desse projeto matemático e lógico: o fazedor de puzzles não tem a peça necessária para terminar seu projeto. Dessa forma, Perec nos apresenta o jogo leitor-autor existente em toda obra, ao mesmo tempo em que revela a impossibilidade de uma programação exata da recepção de qualquer obra literária, mesmo que ela parta de procedimentos matemáticos. De acordo com Compagnon: 
Baseado no leitor implícito, o ato da leitura consiste em concretizar a visão esquemática do texto, isto é, em linguagem comum, a imaginar os personagens e os acontecimentos, a preencher as lacunas de narrações e descrições, a construir uma coerência a partir de elementos dispersos e incompletos. A leitura se apresenta como uma resolução de enigmas (conforme aquilo que Barthes chamava de "código hermenêutico", ou de modelo cinegético, citado a propósito da mimèsis). Utilizando a memória, a leitura procede a um arquivamento de índices. A todo momento, espera-se que ela leve em consideração todas as informações fornecidas pelo texto até então. Essa tarefa é programada pelo texto, mas o texto a frustra também, necessariamente, pois uma intriga contém sempre falhas irredutíveis, alternativas sem escolha, e não poderia haver realismo integral. Em todo texto, existem obstáculos contra os quais a concretização se choca obrigatória e definitivamente (COMPAGNON, 2006, p. 152).

Para Perec, a leitura é também a resolução de enigmas, em cuja descoberta os conhecimentos matemáticos podem ajudar, o erro e a falha existem e são, também, incorporados nessa literatura, aumentando ainda mais sua potencialidade. Em obras como $A$ vida modo de usar, além de caçador e detetive, o leitor é ainda o viajante, já que sua leitura, "como expectativa e modificação da expectativa, pelos encontros imprevistos ao longo do caminho, parece-se com uma viagem através do texto" (COMPAGNON, 2006, p. 152). Esses encontros imprevistos, no livro, são possíveis graças às contraintes matemáticas e, também, às falhas delas resultantes. Nesse jogo, por mais que seja determinante o uso da matemática, o leitor é livre, podendo aceitar buscar, identificar e reconhecer esses artifícios ficcionais ou deixando-os passar e encontrando outros sentidos para a obra. Perguntamo-nos, portanto, o porquê de trabalhar com matemática em Perec, já que ele não era especialista no assunto. Acreditamos que a única resposta possível, coerente e consistente a essa pergunta é que, estudar a matemática nas obras de Perec, é estudar também e simultaneamente sua literatura, sua arte e sua potencialidade. É redescobrir suas obras sob um aspecto diferente, novo e ainda não muito explorado.

Assim um leitor não versado em contraintes e na matemática poderá recepcionar os romances, os pensamentos, as classificações e a ficção de Perec, e ao longo de sua leitura irá esbarrar e descobrir a potencialidade de alguns enigmas e jogos. Tão mais próximo do leitor implícito e do leitor laborioso, mais próximo e mais distante estará de recepcionar a obra de Perec, já que este 
potentielle. Paris: Folio essais, 1973a. p. 73-89.

Palindrome. In: OULIPO. La littérature potentielle. Paris: Folio essais, 1973b. p. 97-102.

La Vie mode d'emploi. Paris: Hachette, 1978a.

Je me souviens. Paris: Hachette, $1978 \mathrm{~b}$.

. L'ARC 76 - Georges Perec. Paris: Librarie Duponchelle, 1979.

. Penser/Classer. Paris: Hachette, 1985.

. Um homem que dorme. Trad. Dalva Laredo Diniz. Rio de

Janeiro: Nova Fronteira, 1988.

53 Jours. Paris: Gallimard, 1989a.

A vida modo de usar. Trad. Ivo Barroso. São Paulo: Companhia das Letras, 1991.

. Cantatrix Sopranica L et Autres Récits Scientifiques. Paris:

Seuil, 1991.

Morton's ob. In: BELLOS, David. Georges Perec: une vie dans les mots. Paris: Éditions Seuil, 1994. p. 703.

W ou a memória da infância. São Paulo: Companhia das Letras, 1995a.

. Récit d'Ellis Island. Paris: P.O.L., 1995b.

. What a man! Paris: Le Castor Éditeur, 1996.

. Jeux intéressants. Paris: Zulma, 1997.

. Nouveaux jeux intéressants. Paris: Zulma, 1998.

. Deux cent quarente-trois cartes postales. In: DENIZE, Antoine. Machines à écrire. Éditions Gallimard. Paris, 1999a (DVD).

. Konzerstück für sprecher und orchester. In: MAGNÉ, Bernard. Georges Perec. Paris: Éditions Nathan Université, 1999b. p. 76.

. Espèces d'espaces. Paris: Galilée, 2000.

. Theatre I. La poche parmentier et Précédé de L'augmentation. Paris: Hachette, 2001a.

- L'augmentation. In: PEREC, Georges. Theatre I. La poche parmentier et Précédé de L'augmentation. Paris: Hachette, 2001b. p. 1-59.

. Alphabets. Paris: Galilée, 2001c.

Romans et Récits. Paris: Librairie Générale Française, 2002a.

Quel petit vélo à guidon chromé au fond de la cour? In:

PEREC, Georges. Romans et Récits. Paris: Librairie Générale Française, 2002b. p. 147-210.

. Les Revenentes. In: PEREC, Georges. Romans et Récits. Paris: Librairie Générale Française, 2002c. p. 563-639.

Tentative d'épuisement d'un lieu parisien. Paris: Christian Bourgois Editeur, 2003a.

Perec entretiens et conférences I. Paris: Joseph K./Centre 
National du Livre, 2003b.

Perec entretiens et conférences II. Editions: Joseph K./Centre National du Livre, 2003c.

A coleção particular. In: PEREC, Georges. A coleção particular. Rio de Janeiro: Cosac Naify, 2005a. p. 7-72.

A viagem de inverno. In: PEREC, Georges. A coleção particular. Rio de Janeiro: Cosac Naify, 2005b. p. 73-82.

Beaux présents, Belles Absents. Paris: Points, 2009a.

Variation sur un thème de Marcel Proust. In: OULIPO. Anthologie de l'OuLiPo. Paris: Gallimard, 2009b. p. 15-20.

A arte e a maneira de abordar seu chefe para pedir um aumento. São Paulo: Companhia das Letras, 2010.

PROUST, Marcel. Du côte de chez Swann. Paris: Gallimard, 1954.

REGGIANI, Christelle. La Rhétorique de l'invention de Raymond Roussel à l'Oulipo, thèse soutenue le 17 novembre 1997 à l'École normale supérieure. 